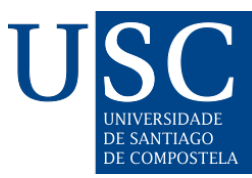

\title{
A xestión da auga nos fogares é unha condición sine qua non da cidade sustentábel do futuro
}

\author{
Household wáter management is a sine qua non of the sustainable city of the \\ future
}

\section{Gumersindo Feijoo}

Universidade de Santiago de Compostela, España

gumersindo.feijoo@usc.gal

\section{Resumo}

No ano 2020 a porcentaxe media da poboación mundial que vivía nas cidades foi do $56 \%$, sendo a media de Europa dun 74\%. Nunha enquisa feita no ano 2021 á poboación europea infírese que os tres principais retos que encara a humanidade son o cambio climático, a falta de auga e a propagación de enfermidades. De feito, a dispoñibilidade de auga limpa e un correcto saneamento da mesma constitúe un dos Obxectivos de Desenvolvemento Sustentábel marcados na Axenda 2030 (ODS 6), polo que cómpre facer unha correcta xestión do ciclo de auga nas cidades, comezando polos sistemas de potabilización, para reducir a pegada hídrica. Os fogares xogan un papel preponderante nesta meta, xa que adaptar o consumo de auga as necesidades reais pode facerse de xeito sinxelo seguindo unha serie de pequenas accións accesibles económica e tecnoloxicamente. Asemade, a I+D+i actual está a debullar a EDAR do século XXI, encamiñando a súa evolución ata o deseño dunha biofactoría capaz de recuperar os recursos materiais e enerxéticos presentes nas propias augas residuais, aspecto compatíbel co seu obxectivo primoxénito de eliminar as substancias contaminantes antes da súa vertedura.

Palabras chave: ODS6; cidade sustentábel; pegada hídrica; consumo de auga; saneamento.

\begin{abstract}
In 2020, the average percentage of the world's population living in cities was $56 \%$, with the average for the European continent being 74\%. A survey of the European population in 2021 suggests that the three main challenges facing humanity are climate change, lack of water and the spread of disease. In fact, the availability of clean water and its proper sanitation is one of the Sustainable Development Goals set out in the Agenda 2030 (SDG 6). Therefore, management of the water cycle in cities, starting with water purification systems, is necessary to reduce the water footprint. Households play a key role in this goal, as adapting water consumption to real needs can be done in a simple way by following a series of small actions that are economically and technologically accessible. Furthermore, the R\&D\&I currently being carried out will shape the WWTP of the 21st century, directing its evolution towards the design of a biofactory capable of recovering the material and energy resources present in wastewater, an aspect that is compatible with its primary objective of removal pollutants before they are discharged.
\end{abstract}


Keywords: SDG6; sustainable city; water footprint; water consumption; sanitation.

\section{Sumario}

1. Cidades e cidadáns

2. Consumo de auga e pegada hídrica

3. Xestión da auga e cambio climático

4. Boas prácticas na xestión da auga nos fogares

5. Saneamento no século XXI

\section{Contents}

\section{Cities and citizens}

2. Water consumption and water sticking

3. Water management and climate change

4. Good practices in household water management

5. Sanitation in the 21st century

\section{CIDADES E CIDADÁNS}

Dende finais do século XX, estase a producir un aumento continuado da poboación mundial que vive nas cidades (Figura 1) e no ano 2020, a media mundial xa atinxiu un valor do 56\%, existindo diferencias substanciais para os diversos continentes (Figura 2). Así, os países de América do Norte sitúanse á cabeza cunha porcentaxe do 82\%, seguidos de Hispanoamérica (81\%) e Europa (74\%). Ademais, existe unha tendencia imparábel no aumento do número de megacidades (aquelas que superan os 10 millóns de habitantes e cunha densidade de poboación preto das 2.000 persoas por km2). Os territorios que maioritariamente están a crecer son os países emerxentes como China e India (Hoornweg e Pope, 2016). En 2010, 757 millóns de persoas residían nas 101 cidades máis grandes, o 11\% da poboación mundial. Para finais de século, as diferentes estimacións demográficas sinalan que a poboación mundial pode oscilar entre 6.900 e 13.100 millóns de persoas, das cales entre o 15-23\% poderían residir nas 101 megacidades. 
Figura 1. Evolución da porcentaxe da poboación que vive en cidades nos últimos 70 anos en España, Portugal e no Mundo

Poboación nas cidades (\%)

1950-2020

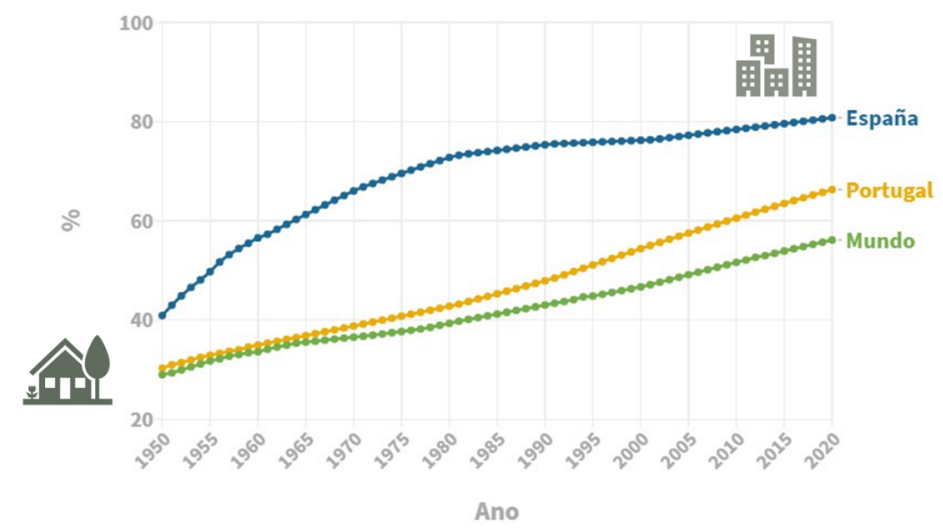

Fonte dos datos: Banco Mundial.

Este movemento demográfico fai que as cidades pasen a xogar un papel preponderante na procura dunha sociedade sustentábel. A cidade do futuro definirase inescusabelmente, entre outros factores, por atinxir unha boa xestión das entradas e saídas de materia e enerxía nos fogares. Así, existen tres situacións que provocan tamén gran inquedanza nos fogares pola súa ausencia (enerxía e auga) ou acumulación (residuos).

Figura 2. Distribución porcentual da poboación que vive en cidades no 2020 para cada un dos países. Os puntos simbolizan as cidades con maior poboación.

Poboación en cidades (\%)

2020
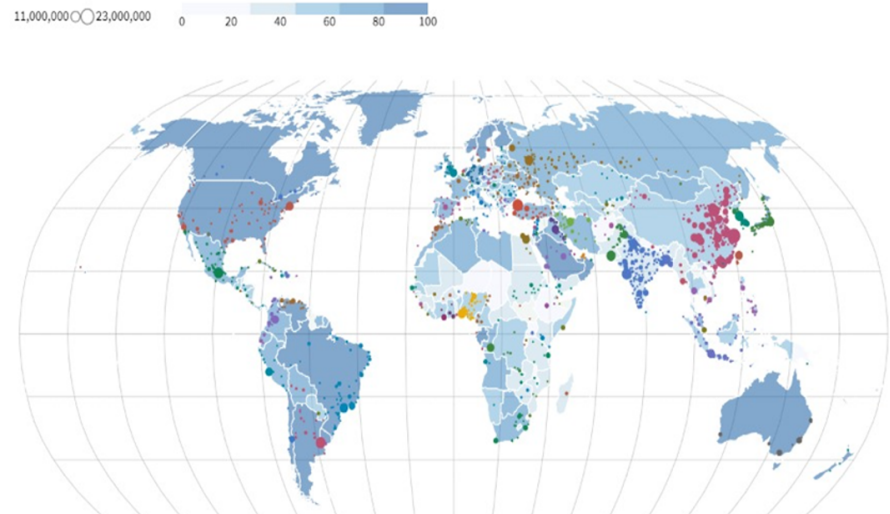

Fonte dos datos: Banco Mundial.

En xullo de 2021, o eurobarómetro publicou os resultados (Eurobarometer, 2021) das enquisas realizadas a uns 26.000 cidadáns dos diferentes países da UE co obxectivo de coñecer cales son os problemas máis graves que ten por diante a humanidade (Figura 3). Os tres primeiros problemas para a poboación europea (UE27) corresponderon a: (i) cambio climático; (ii) pobreza, fame e falta de auga; e (iii) propagación de enfermidades (claro exemplo do impacto da COVID-19). Os cidadáns españois coinciden basicamente na listaxe priorizada dos problemas, pois dous dos problemas 
relacionados co medio ambiente (cambio climático e falta de auga) atópanse entre os que presentan maior importancia, relegando a propagación de enfermidades ao cuarto lugar, xa que a sempiterna cuestión da situación económica ocupou a primeira posición.

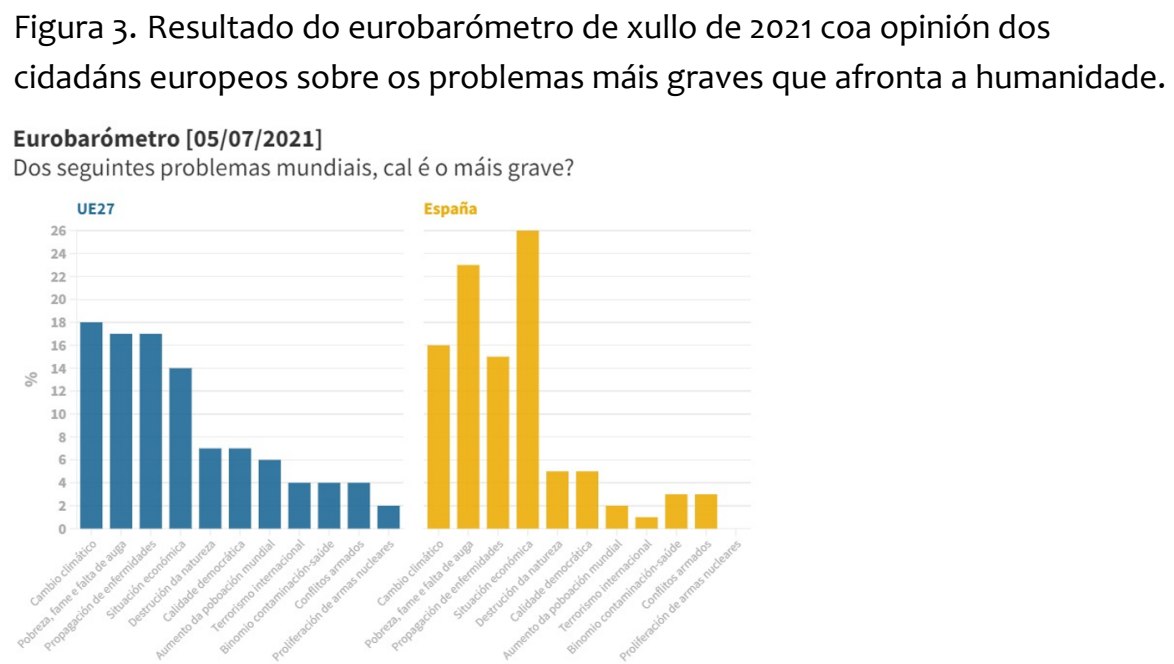

A ONU pola súa parte tamén puxo o foco na cuestión da auga, pois nos Obxectivos de Desenvolvemento Sustentábel (ODS) enmarcados na Axenda 2030 adica o número 6 á "Auga Limpa e Saneamento". Actualmente existen millóns de persoas que carecen de servizos básicos de acceso á auga potábel, con datos claramente demostrativos desta situación tan problemática: unha de cada tres persoas non ten acceso á auga potábel salubre e dúas de cada cinco persoas non dispoñen dunha instalación básica destinada a lavarse as mans con auga e xabón. A peste da COVID-19 puxo de manifesto a importancia transcendental do saneamento, a hixiene e o acceso axeitado á auga limpa para prever e conter as enfermidades. A Organización Mundial da Saúde (OMS), sinalou dende o primeiro momento que o lavado das mans era unha das accións máis efectivas que se podían facer para reducir a propagación de patóxenos e facer unha profilaxe fronte ás infeccións, incluído o virus da COVID-19. Polo tanto, non cabe dúbida que a dispoñibilidade de auga e o seu correcto saneamento, así como reducir a pegada hídrica son retos que a sociedade ten na actualidade para atinxir un futuro sustentábel.

\section{CONSUMO DE AGUA E PEGADA HÍDRICA}

0 acceso á auga no mundo é bastante desigual, existindo unha clara diferenza entre os países do hemisferio norte e sur, pois no continente africano as infraestruturas hidráulicas son escasas ou practicamente nulas. Se analizamos o continente europeo, onde o desenvolvemento de infraestruturas hidráulicas é moi semellante, o consumo medio de auga nos fogares no ano 2018 foi de 50,2 m3 por habitante (aproximadamente uns $138 \mathrm{~L}$ diarios). Agora ben, existen variacións notábeis entre os diferentes países; por exemplo, $53 \mathrm{~m} 3 /$ hab de España, $69 \mathrm{~m} 3 /$ hab de Italia ou 107 m3/hab de Grecia (Figura 4). 
Figura 4. Consumo de auga ( $\mathrm{m} 3$ anuais/habitante) nos fogares para algúns países europeos no ano 2018.

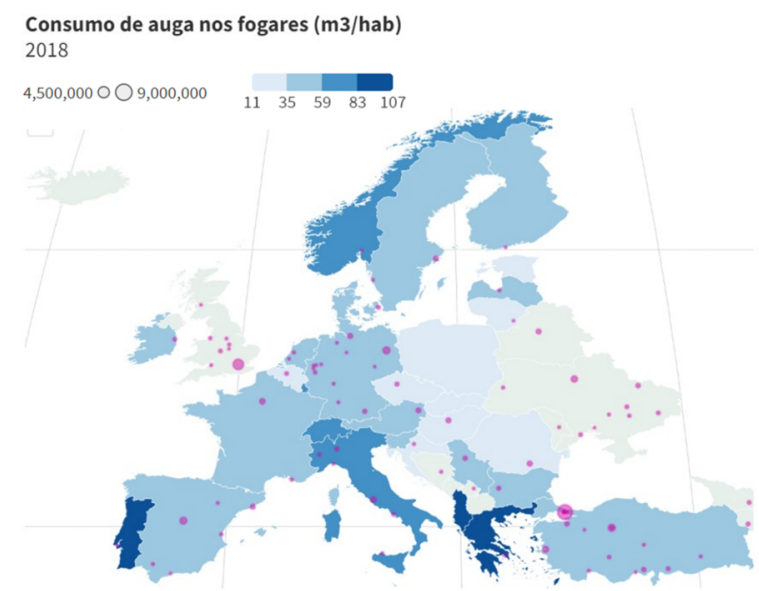

Fonte dos datos: Banco Mundial e Eurostats.

A pegada hídrica é un indicador ambiental que cuantifica o volume total de auga doce usada ao longo de toda a cadea de valor dos produtos, procesos ou servizos. Aplícase ao cálculo de bens e servizos consumidos por un individuo, unha comunidade, un produto ou unha empresa. Existen dúas metodoloxías de cálculo para este indicador: a descrita pola rede de pegada hídrica (WFN, polas súas siglas en inglés) ou a definida pola norma ISO 14046:2014.

Segundo o enfoque da WFN, a pegada hídrica pódese dividir en tres tipos de indicadores en función da súa procedencia:

- Auga verde: relacionada coa auga de choiva incorporada no produto ou a evapotranspirada polas plantas.

- $\quad$ Auga azul: relacionada co consumo de auga doce.

- $\quad$ Auga gris: relacionada coa calidade da auga e a súa contaminación debido á vertedura de substancias contaminantes nun proceso.

Pola contra, a ISO 14046 basease na metodoloxía da Análise de Ciclo de Vida (ACV) descrita pola ISO 14040:2006. A aplicación da filosofía de ciclo de vida implica a avaliación dos impactos ambientais directos e indirectos dende o berce ata a cova, incluíndo a cuantificación das cargas ambientais asociadas ás etapas de extracción de materias primas, transporte, produción, distribución, uso e fin de vida. En consecuencia, a norma ISO 14046 non só contabiliza o volume de auga consumido, senón que tamén avalía os posibles impactos medioambientais relacionados con devandito consumo mediante o uso de indicadores relacionados coa auga.

Nun estudo publicado no ano 2018 por González-García e col. analizouse o impacto ambiental de 26 cidades españolas coa metodoloxía da ACV. A mostra das cidades tivo en conta os datos de poboación, hábitos e a súas características sociais, económicas e xeográficas (Táboa 1). 
Táboa 1. Cidades consideradas no estudo sobre impactos ambientais dende a perspectiva de ciclo de vida (González-García e col., 2018).

\begin{tabular}{|c|c|c|c|}
\hline Cidade & Poboación (habitantes) & $\begin{array}{l}\text { Densidade de poboación } \\
\text { (hab./ } / \mathrm{km}^{2} \text { ) }\end{array}$ & PIB (€/hab.) \\
\hline A Coruña & 243.978 & 6.613 & 26.450 \\
\hline Alacante & 330.525 & 1.677 & 25.246 \\
\hline Badaxoz & 149.946 & 100 & 24.556 \\
\hline Barcelona & 1.608 .746 & 16.000 & 32.954 \\
\hline Bilbao & 345.122 & 8.300 & - \\
\hline Córdoba & 326.609 & 260 & 23.720 \\
\hline L'Hospilatet de Llobregat & 378.998 & 3.800 & 26.159 \\
\hline Las Palmas & 252.171 & 20.000 & 23.092 \\
\hline Logroño & 150.876 & 1.900 & 25.554 \\
\hline Madrid & 3.165 .541 & 5.390 & 34.122 \\
\hline Málaga & 569.009 & 1.430 & 23.955 \\
\hline Murcia & 441.003 & 500 & 24.846 \\
\hline Oviedo & 220.567 & 1.200 & 27.339 \\
\hline Palma de Mallorca & 402.949 & 1.900 & 26.379 \\
\hline Pamplona & 195.650 & 8.300 & - \\
\hline Santa Cruz de Tenerife & 203.585 & 1.400 & 26.020 \\
\hline Santander & 172.656 & 5.100 & 27.167 \\
\hline Santiago de Compostela & 95.966 & 430 & 26.213 \\
\hline Sevilla & 690.566 & 5.002 & 26.605 \\
\hline Toledo & 83.459 & 360 & 26.296 \\
\hline Valencia & 790.201 & 6.000 & 26.928 \\
\hline Valladolid & 301.876 & 1.525 & 25.624 \\
\hline Vigo & 292.817 & 2.700 & 24.733 \\
\hline Vitoria-Gasteiz & 244.634 & 880 & - \\
\hline Xixón & 276.001 & 1.500 & 25.518 \\
\hline Zaragoza & 661.108 & 680 & 26.340 \\
\hline
\end{tabular}

0 valor medio da pegada hídrica para a mostra de cidades españolas consideradas foi de $64 \pm 9$ m3 por habitante equivalente e ano. Existe unha flutuación significativa entre as diferentes cidades que está directamente relacionada coas taxas de consumo de auga (Figura 5). Unha das cuestións máis relevantes é que non existe unha relación directa entre aquelas zonas climáticas sometidas a un maior estrés hídrico e unhas pegadas hídricas máis pequenas, xa que son os hábitos das cidades as que determinan en maior proporción os datos finais de consumo de auga. 
Figura 5. Pegada hídrica de diferentes cidades españolas (González-García e col., 2018).

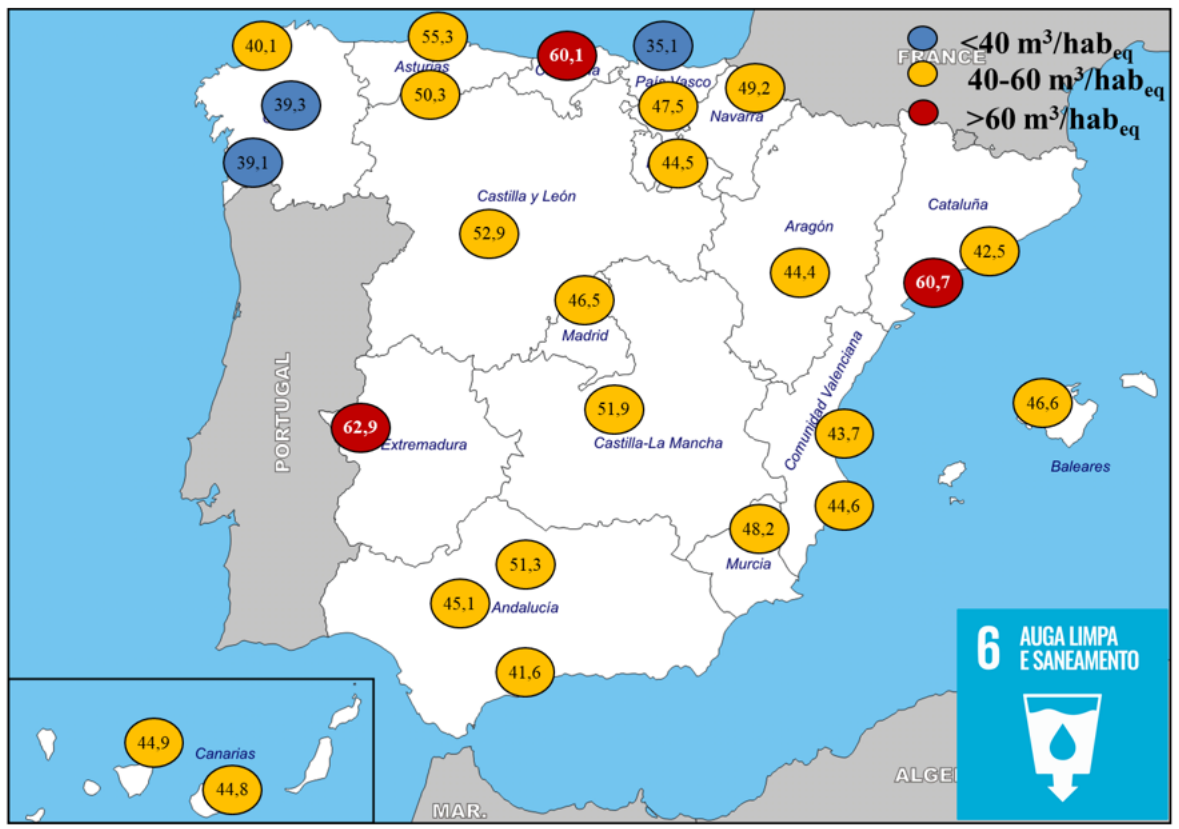

\section{XESTIÓN DA AUGA E CAMBIO CLIMÁTICO}

0 réxime de precipitacións e a duración das secas están a mudar de xeito acelerado, produto da emerxencia climática que estamos a vivir polo quecemento constante e paulatino do planeta. Por todo isto, un consumo responsábel da auga ten que ser unha prioridade do noso comportamento ético.

Minimizar o consumo de auga non só ten efecto sobre unha boa xestión dos recursos hídricos, senón que tamén está intimamente relacionado co cambio climático. Así, a potabilización de augas implica un valor medio de $350 \mathrm{~g}$ de CO2eq por m3, debido ás emisións indirectas dos compostos químicos e enerxía que se consumen nas diversas operacións de tratamento físico e químico nas estacións potabilizadoras de augas (Figura 6). De feito, "fabricar" unha auga de tan alta calidade para que parte da mesma se empregue finalmente na cisterna dunha latrina supón unha das aberracións máis cotiás que nos podemos atopar nunha casa. Asemade, o consumo de auga tamén deriva nun caudal de auga residual que á súa vez debe tratarse nunha estación depuradora de augas residuais, cunha emisión media de 500 g de CO2eq por m3, para eliminar a contaminación orgánica que contén. A estas dúas etapas cómpre engadir os impactos derivados da rede de distribución de auga potábel e da rede de sumidoiros. Polo tanto, no intre no que se está a discutir a necesidade dunha redución drástica das emisións de dióxido de carbono, cómpre ser consciente dos procesos e accións que contribúen en maior ou menor medida á emisión de gases de efecto invernadoiro. 
Figura 6. Proceso estándar de potabilización da auga, no cal están involucradas diversas etapas de tratamento físico e químico.

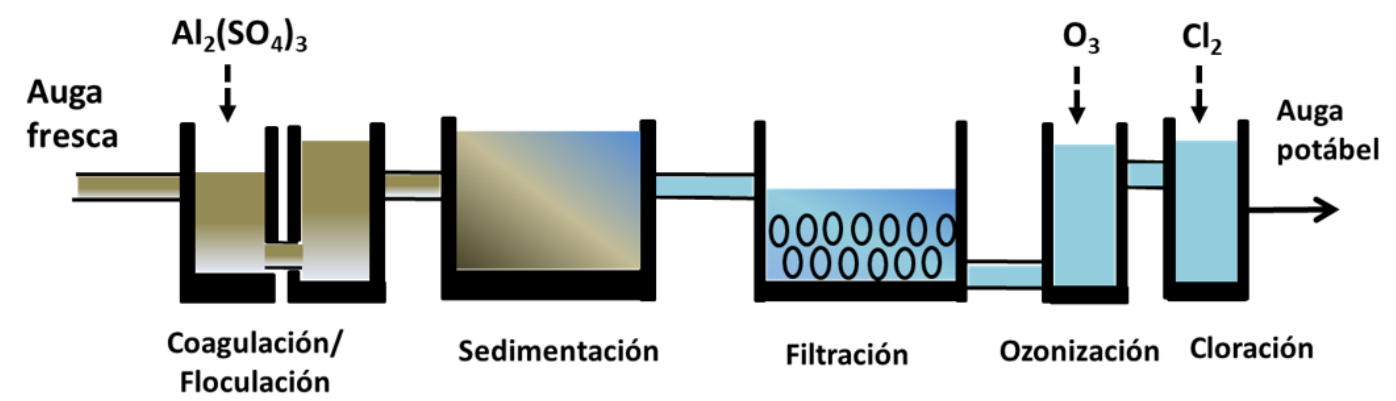

\section{BOAS PRÁCTICAS NA XESTIÓN DA AUGA NOS FOGARES}

Nos fogares podemos seguir un conxunto de boas prácticas encamiñadas a unha redución de consumo de auga que vai supor efectos positivos directos sobre a economía familiar pero que tamén vai contribuír a un mellor desempeño ambiental (Figura 7). Entre as principais accións pódense destacar:

- Evitar as pingueiras das billas, xa que cada unha delas pode chegar a significar unha perda de ata $30 \mathrm{~L}$ diarios. Esta cantidade significa, aproximadamente, o volume de auga que bebe comunmente unha familia de 3 membros durante unha semana laborábel.

- Pechar as billas da ducha cando non se emprega, xa que cada minuto aberta supón un gasto de $20 \mathrm{~L}$. Un par de minutos diarios nunha familia de tres membros supón ao longo do mes un volume de $3,6 \mathrm{~m} 3$.

- Unha lavadora ten un consumo que oscila entre 50 e $100 \mathrm{~L}$ e as lavalouzas poden chegar aos 50 L. Optar por modelos que minimicen a pegada hídrica é sempre unha boa opción.

- Os inodoros gastan uns $10 \mathrm{~L}$ cada vez que tiramos da cisterna. Neste caso hai diversas opcións no mercado: (i) empregar auga dos lavadoiros ou pluviais para as cisternas (as denominadas augas verdes) e (ii) minimizar o consumo de auga ao optar por inodoros que operan á baleiro (similares aos dos avións, aínda que neste último caso existen problemas a resolver como o ruído que producen).

- 0 rego debe combinarse cunha optimización da auga necesaria (por exemplo, o sistema de gota a gota) co emprego de augas grises ou rexeneradas. 
Figura 7. Boas prácticas sinxelas para minimizar o consumo de auga no fogar.

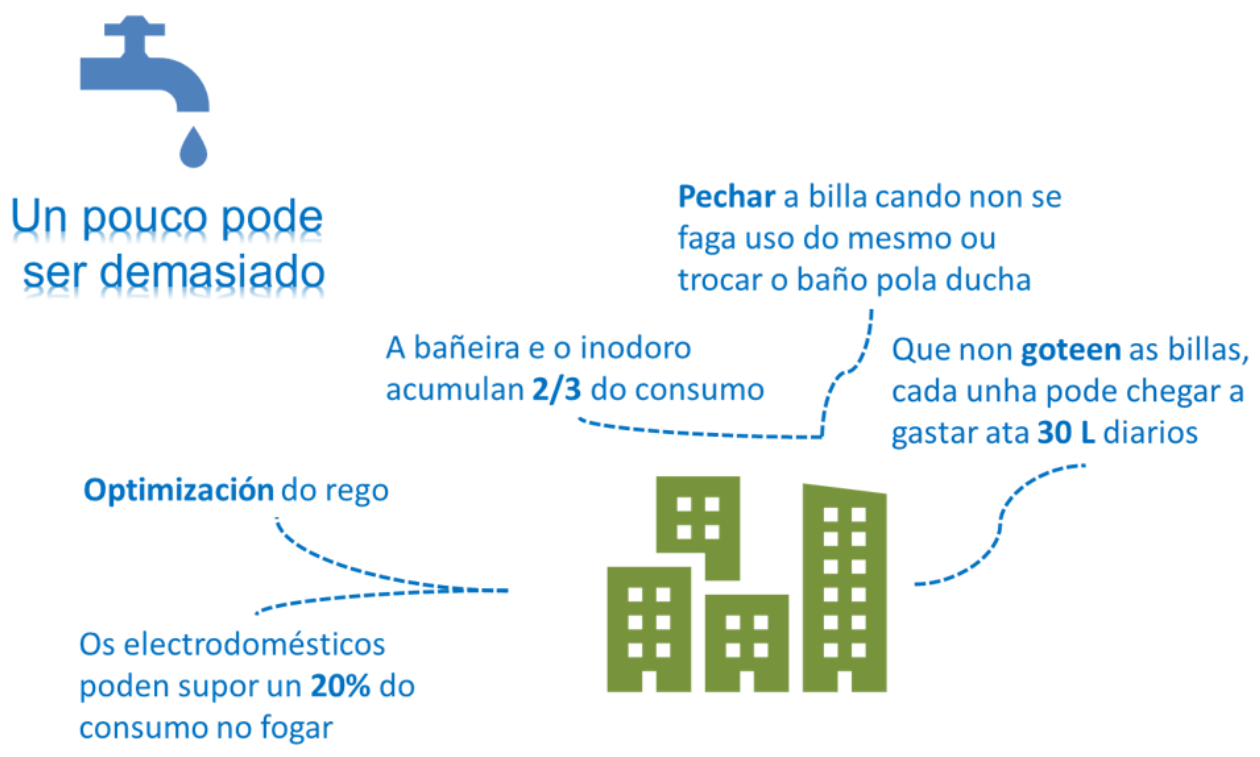

\section{SANEAMENTO NO SÉCULO XXI}

As estacións de depuración de augas residuais (EDAR) que se operan actualmente xa teñen introducidos os conceptos de innovación desenvolvidos a finais do século XX, nos que non só a eliminación de carbono (procesos de aerobios e anaerobios) senón tamén de nitróxeno (procesos de nitrificación-desnitrificación) e fósforo están contemplados co gallo de minimizar os impactos de eutrofización que a vertedura das augas residuais tratadas poidan ter nos leitos dos ríos e lagoas (Lema e Suárez, 2017).

Entre as principais liñas de investigación actuais que virarán o deseño e operación das EDAR nos vindeiros anos podemos destacar:

- Descentralización vs centralización dos sistemas de saneamento. Mentres que as plantas de tratamento de augas residuais centralizadas deben evolucionar no seu deseño e funcionamento para adaptarse a un escenario de crecente demanda de auga, enerxía e recursos, o enfoque descentralizado xurde como a opción a considerar en pequenas comunidades ou zonas residenciais onde a produción de bioenerxía pode mellorarse a través da recuperación da materia orgánica ou onde a inversión na rede de sumidoiros para a conexión a unha instalación centralizada pode ser tecnolóxica ou economicamente inviábel (Estévez e col., 2021). Unha visión a longo prazo desta hipótese sería considerar cada casa ou rueiro como a estación espacial orbital e que se puidese integrar nun aproveitamento autosuficiente do ciclo da auga.

- Micro- e nanocontaminantes. As novas directivas europeas fan fincapé na importancia de eliminar das augas residuais os micro- e nanocontaminantes ou contaminantes emerxentes, constituídas por aquelas substancias químicas orgánicas, naturais ou de síntese, que tras o seu uso chegan ás EDARs, onde están presentes en concentracións moi baixas (ppb - parte por billón, $\mu \mathrm{g} / \mathrm{L}$-; ou ppt - partes por trillón, ng/L -). Na Táboa 2 reflíctese unha escolma 
do tipo de compostos químicos que se poden atopar nas EDAR. A súa eliminación implica o desenvolvemento e optimización de novos sistemas físicos-químicos, como os sistemas de oxidación avanzada (González-Rodríguez e col., 2021), e biolóxicos (Arias e col., 2018; Lloret e col., 2013).

Táboa 2. Escolma de micro- e nanocontaminantes que se poden atopar nas augas residuais

\begin{tabular}{|l|l|l|l|}
\hline Antibióticos & $\begin{array}{l}\text { Analxésicos e } \\
\text { antiinflamatorios }\end{array}$ & Fragrancias & Ftalatos \\
\hline Ciprofloxacina & Diclofenaco & Galaxolida & Ftalato de dimetilo \\
\hline Eritromicina & Ibuprofeno & Tonalide & Ftalato de diisobutilo \\
\hline Ofloxacina & Naproxen & Antidepresivos & Desinfectante \\
\hline Sulfametoxazol & Disruptores endrocrinos & Fluoxetina & Triclosan \\
\hline Tetraciclina & Estradiol & Psicoestimulantes & Medios de contraste \\
\hline Antiepilépticos & Etinilestradiol & Cafeína & lopromuro \\
\hline Carbamazepina & Bifenol A & Paraxantina & lomeprol \\
\cline { 4 - 4 } & & & lopamidol \\
\hline
\end{tabular}

- $\quad$ EDAR vs Biofactoría. Evolucionar o concepto das EDAR como instalacións adicadas ao tratamento das augas residuais e evitar a vertedura de substancias contaminantes, ao deseño de biofactorías orientadas ao aproveitamento da enerxía e recursos materiais que posúe a propia auga residual. Neste senso, a obtención de bioplásticos; por exemplo, os PHA (Polihidroxialcanoatos, polímeros formados basicamente por cadeas de hidroxibutirato e valeratos) é unha das opcións que se barallan. Outra opción que tivo un relanzamento é a obtención directa de fertilizantes, máis aló do uso de lodos estabilizados, como, por exemplo, a estruvita (un fosfato hidratado de amonio e magnesio) (Crutchik e col., 2017).

\section{REFERENCIAS BIBLIOGRÁFICAS}

Arias, A., Alvariño, T., Allegue, T., Suárez, S., Garrido, J.M., Omil, G. (2018). An innovative wastewater treatment technology based on UASB and IFAS for cost-efficient macro and micropollutant removal. Journal of Hazardous Materials, 359, 113-120. https://doi.org/10.1016/j.jhazmat.2018.07.042.

Crutchik, D., Rodrigues, S., Ruddle, D., Garrido, J.M. (2017). Evaluation of a low-cost magnesium product for phosphorus recovery by struvite crystallization. Journal of Chemical Technology and Biotechnology, 93(4), 1012-1021. https://doi.org/10.1002/jctb.5453.

Estévez, S., González-García, S., Feijoo, G., Moreira, M.T. (2021). How decentralized treatment can contribute to the symbiosis between environmental protection and resource recovery. The Science of The Total Environment. https://doi.org/10.1016/j.scitotenv.2021.151485.

Eurobarometer (2021). Special Eurobarometer 513. Climate Report. https://europa.eu/eurobarometer/sur veys/detail/2273.

González-García, S., Manteiga, R., Moreira, M.T., Feijoo, G. (2018). Assessing the sustainability of Spanish cities considering environmental and socio-economic indicators Journal of Cleaner Production, 178, 599-610. https://doi.org/10.1016/j.jclepro.2018.01.056. 
González-Rodríguez, J., Gamallo, M., Conde, J.J., Vargas-Osorio, Z., Vázquez-Vázquez, C., Piñeiro, Y., Rivas, J., Feijoo, G., Moreira, M.T. (2021). Exploiting the potential of supported magnetic nanomaterials as Fenton-like catalysts for environmental applications. Nanomaterials, 11(11), 2902. http://doi.org/10 $.3390 /$ nano11112902.

Hoornweg, D., Pope, K. (2016). Population predictions for the world's largest cities in the 21st century. Environment \& Urbanization, 29(1), 195-216. http://doi.org/10.1177/0956247816663557.

ISO 14040:2006. Environmental management - Life cycle assessment - Principles and framework. ISO Standars.

ISO 14046:2014. Environmental management - Water footprint — Principles, requirements and guidelines. ISO Standars.

Lema, J.M., Suárez, S. (2017). Innovative Wastewater Treatment \& Resource Recovery Technologies: Impacts on Energy, Economy and Environment. IWA Publishing.

Lloret, L., Eibes, G., Moreira, M.T., Feijoo, G., Lema, J.M. (2013). Removal of estrogenic compounds from filtered secondary wastewater effluent in a continuous enzymatic membrane reactor. Identification of biotransformation products. Environmental Science and Technology, 47(9), 4536-4543. https://doi.or g/10.1021/es304783k.

WFN -Water Footprint Network- (2021) https://waterfootprint.org/en/.

NOTAS

Gumersindo Feijoo é profesor do departamento de Enxeñaría Química e membro do Centro Singular CRETUS da USC. As súas liñas de investigación están enmarcadas na Enxeñaría Bioquímica e na Enxeñaría Ambiental, especificamente nos aspectos da economía circular coa aplicación da análise de ciclo de vida e pegadas ambientais ao deseño de produtos e procesos máis sustentábeis. Ten participado en diversos proxectos europeos e nacionais que derivaron na publicación de máis 275 artigos en revistas incluídas no JCR (cun índice h superior a 60) e 7 patentes (das cales dúas atópanse en explotación).

Contacto: gumersindo.feijoo@usc.gal 